collection of cases and meticulously careful observations. His colleague, Barbara Ockenden, prepared his draft for publication. The huge total of 1,168 neoplasms verified at Great Ormond Street Hospital in the last 37 years are classified and reviewed.

Steroid treatment in asthma, which tends to be abused and must be supervised with great care, is discussed by Norman; and the technique and value of renal biopsy are reviewed by Black and White who are themselves leading authorities on the subject. Finally, Macnab, in the two concluding chapters, has reviewed the striking advances which have been achieved in the past few years in the understanding and management of hydrocephalus and spina bifida cystica in infancy.

Postgraduate Courses in Pediatrics. Vol. 15. Leberkrankheiten beim Kind. Edited by E. Rossi. (Pp. ii +84 ; 13 figures +16 tables. sFr./DM.15.) Basel: S. Karger. 1965.

This Swiss paper-back presents a brief and uneven review of liver disease in childhood. Six chapters are in German and one in French.

Vest's account of bilirubin metabolism is lucid but becomes less so when dealing with the (admittedly confusing) eponymous and often familial types of jaundice. Much the same ground is covered by the French contributor who does, however, give some idea of the relative frequency of liver disease, particularly in early childhood. Even so, the rarer and rarest types of jaundice remain a jumble.

By far the best contribution is Richterich's chapter on liver cell physiology and the physiological basis, specificity, significance, and limitations of liver function tests.

The account of needle biopsy scarcely does justice to a most valuable procedure.

Mangold's comprehensive but haphazard list of childhood cirrhosis may be a boon to examination candidates who possess a photographic memory.

The chapter on serum hepatitis is satisfactorily adequate. The final contribution, in railway-timetable style, on the definition, aetiology, and treatment of hepatic coma appears to have been an editorial afterthought.

The bibliography of one of the chapters is arranged neither numerically nor alphabetically-most infuriating. Another chapter has no bibliography at all. The booklet is well printed but badly bound, and has no index.

Practical Paediatrics. By Don Hilson. (Pp. 462; 28 figures +16 diagrams. 84s.) London: Staples Press. 1964.

Dr. Hilson's book is unusual. From its title it is evidently intended as a practical guide rather than an academic text, and on the cover it is stated that 'it should be particularly valuable as a practical aid to the graduate in the paediatric ward, and to the family practitioner in his day-to-day work'. To this end it is written in the style of a tutorial, with direct instructions and many tabulated lists. The aims of the book are high, but perhaps Dr. Hilson has underestimated the difficulties of attaining them. It is one thing to talk to a small group of students on selected topics, but another matter to record this in cold print and at the same time to extend the topics to cover virtually the whole field of paediatrics. It is doubtful if our greatest teachers-men like Robert Hutchison-would have succeeded, but then they would not have tried. The loose phrase which may pass unnoticed in extempore speech is laid bare to cold analysis; the ambiguity which can be corrected by simple question and answer at the end of a seminar remains unresolved. Unfortunately the book abounds in careless phrases, and one fears that careless writing points to muddled thinking. What can one make of a paragraph such as this?-

'Give Thyroid extract B.P. commencing with $15 \mathrm{mgs}$. or grs. $\frac{1}{4}$, or use thyroxine sodium $0.025 \mathrm{mgs}$. daily gradually increasing the dosage to just short of toxicity. This produces diarrhoea, irritability, loss of weight and tachycardia in infancy, and in addition in older children, palpitations, sweating and fainting. This must be continued for life.'

To detail the many faults would be too great a task for a short review. In view of the immense amount of work that has gone into the preparation of this book, I feel deeply sorry to have to say that because of its inaccuracies and because of the bad example of its thought and writing I should not like it to be read by any of my students.

Asian Pediatrics. The Scientific Proceedings of the First All-Asian Congress of Pediatrics New Delhi, January 1961. Edited by SisiR K. Bose and A. K. Dey. (Pp. $\mathrm{xx}+$ 476; illustrated. 160s.) London: Asia Publishing House. 1965.

This volume comprises the Scientific proceedings of the first All-Asian Congress of Pediatrics held in New Delhi in 1961.

It contains contributions under the following headings: nutrition; the gastro-intestinal system; infectious diseases; the respiratory system; the cardiovascular system; the haemopoietic system; the genito-urinary system; the skin; the nervous system; social pediatrics; growth and development; and miscellaneous. There are 140 contributors.

The Adolescent in Psychotherapy. By Donald J. Holmes. (Pp. xviii + 337. 67s. 6d.) London: J. \& A. Churchill. 1964.

In the author's opinion empiricism is still superior to theory in the day-to-day practice of psychiatry. Many a psychiatrist observing his internist colleagues may think that this applies fairly widely in their domain too. Dr. Holmes succeeds remarkably well in presenting clinical material and technical subtleties (inevitably difficult for the non-psychiatrist) lucidly and in well-disciplined language. Indeed, what he has to say should be of real 
value to the general clinician who is interested in helping difficult adolescents to grow up as persons.

The book is in 3 parts. Part 1 , which is much the longest, is probably more relevant than Parts 2 and 3 to those wanting to learn more of adolescents, adolescence, the interaction between adult and adolescent, and psychotherapeutic processes.

Part 2, which deals with certain aspects of individual psychotherapy, and Part 3, which discusses residential treatment, are of less immediate concern to those who are not psychiatrists or psychologists.

The book is not one into which the reader can profitably merely dip: it merits careful reading by paediatricians at any rate to the end of Part 1 , and by junior psychiatrists from the beginning to the end. These young people between the 12th and 18th years of life who are no longer children nor yet adults can be very rewarding patients, and Dr. Holmes has performed a useful service in giving us this book. It is a pity that it is rather costly.

Endokardfibrosen. Klinik-Therapie-Pathologie. By Rudolf Wenger. (Pp. viii $+206 ; 42$ figures +14 tables. DM. 30.) Stuttgart: Georg Thieme. 1964. In a monograph of 200 pages and including 700 references, Dr. Wenger endeavours to give us a synoptic work on the whole range of endocardial fibroses. About half of the book deals with primary endocardial fibroelastosis of infancy and childhood, the remainder with fibroelastosis in adolescence and adult life, endomyocardial fibrosis, parietal fibroplastic endocarditis, and endocardial fibrosis in the carcinoid syndrome and in sclerodermia.

This study is based on 800 published cases of childhood fibroelastosis to which the author adds 34 cases of his own or referred to him by his colleagues. His main aîms are to demonstrate that fibroelastosis is not limited to infancy and early childhood but that there exist transitional types of the disease encountered at puberty and in adults, and that there are. links between primary congenital and secondary acquired forms. A schematic presentation shows the interrelation of these pathological manifestations. Though each aspect of primary fibroelastosis is discussed extensively, in the end the profusion of detail leaves the reader with a somewhat blurred picture, in the same way as comprehensive bibliographical reviews which contain contradictory opinions on a particular subject.

The appended 34 brief case histories of childhood fibroelastosis are recorded without critical personal evaluation. From the clinical point of view the presence of organic heart murmurs is regarded as compatible with the diagnosis, while a number of authors stipulate absence of such bruits as a diagnostic criterion.

The rapid accumulation of medical knowledge has also overtaken this book in spite of the author's obvious effort to be up to date. Thus the diagnostic significance of the mumps antigen skin test, which seems to be a most useful procedure, has missed its entry into its pages. Though a considerable section of the monograph is concerned with conditions unlikely to occur in childhood, its exhaustive discussion of the problem of fibroelastosis makes it very interesting reading, especially for the paediatric cardiologist and all those that are engaged in research into the various facets of endocardial fibroses.

As one might expect, the production of the book by the Georg Thieme publishing company of Stuttgart is of a high standard. Paper, print, and reproduction of the black and white photographs are excellent.

\section{Blutkrankheiten im Kindesalter. Postgraduate Courses in}

Pediatrics. Edited by E. Rossi. Vol. 11-12: (Pp. 158; illustrated; 48s.) Basel and New York: S. Karger. 1964.

Among the 8 small volumes edited since 1961 by Ettore Rossi as postgraduate courses in paediatrics, this is one of the most instructive. It contains 9 articles, 7 in German and 2 in French, reviewing not only the progress so far achieved in the study of blood diseases in childhood but also spotlighting the haematological problems still to be solved. The difficulties facing the research worker engaged in the study of leukaemias in the young are presented in a masterly way. A stimulating discussion deals with the various aspects of lymphocytosis and lymphopenia. On one condition the author puts a great deal of emphasis and regrets that only very few paediatricians are aware of its existence, namely "chronic constitutional neutropenia with lymphocytosis'. It occurs from early infancy up to the age of 3 years, predisposes to infections of the upper respiratory tract, hyperthermia, and recurrent bouts of pyrexia. The children prone to the disorder are described as of "partially allergic, partially degenerative and partially dyscranial constitution'. The Teviewer felt that because of the rather nebulous nature of the syndrome and/or its description, most paediatricians might justifiably plead ignorance.

Somewhat disconcerting also are the author's views on the value of the Paul Bunnel test in infectious mononucleosis, to which he accords only a $10 \%$ diagnostic reliability.

The chapters on metabolic disorders of the red cells, mechanisms of haemolysis, aplastic anaemia, structural defects of human haemoglobin, as well as on the development of the red cells and the relationship to the anaemias are well written and illuminating.

The references are well selected and up to date, except for the chapter on thrombocytopenias where they have been omitted.

The section on the function of the platelets is well documented.

One further minor omission occurs in the discussion of steroid therapy of thrombocytopenic purpura where the initial dose is given as $3 \mathrm{mg} . / \mathrm{kg}$. bodyweight but no mention is made of the type of steroid recommended.

In spite of the few criticisms, this is an excellent survey of paediatric haematology and could profitably be read by any paediatrician. 